\title{
Information for Contributors
}

\section{American Journal of Orthopsychiatry \\ http://ww.apa.org/journals/ort.html}

The Journal is dedicated to informing public policy and professional practice and to the expansion of knowledge relating to mental health and human development from a multidisciplinary and interprofessional perspective. Especially welcome for editorial consideration are clinical, theoretical, research, or expository papers that are essentially synergistic and directed at development of concept or theory, reconceptualization of major issues, explanation, and interpretation. Selection of articles for publication is based on originality, adequacy of method, significance of findings, contribution to theory, relevance to service delivery and public policy, and clarity and brevity of presentation.

Articles published in the Journal are selected from unsolicited submissions, papers invited by the Editor, and manuscripts of presentations at the American Orthopsychiatric Association's annual meeting. Whatever their source, all articles considered for publication in the Journal are subject to a process of masked peer review.

Manuscripts of papers presented at Ortho's annual meeting, and intended for publication, must be submitted in timely fashion to the Journal in accordance with submission guidelines. Publication elsewhere than in the Journal or by the Association is prohibited prior to release by the Editor.

Manuscripts must be submitted exclusively for publication in the American Journal of Orthopsychiatry. Papers previously published or now under consideration elsewhere are not eligible for editorial review.

Submissions should be in quadruplicate, typed on one side of firm paper, double-spaced, and with generous margins. Manuscripts should be in final form, with consistent headings and subheadings in roman typeface (i.e., no boldface, italics, etc.) and have an abstract of no more than 120 words. They should be prepared for masked review (i.e., with one title page free of author[s] name[s], and a text free of obvious author-identifying references), and accompanied by a covering letter with mailing address, daytime telephone number, and fax number (if available).

The entire manuscript, including quotations, footnotes, references, and tables, must be double-spaced.

Footnotes should be worked back into the text or deleted, if possible. Where essential, they should appear on a page by themselves following the references and be indicated by superscript arabic numerals.

References should conform with the style set forth in the Publication Manual of the American Psychological Association (5th ed.).

Only photocopies or computer-generated duplicates should be submitted, since rejected manuscripts are disposed of following review.

The American Orthopsychiatric Association assumes no responsibility for any statements of fact or opinion in the papers printed. Nor does acceptance of advertising in the Journal imply endorsement by the Association of any products or services advertised.

The Editorial Board reserves the right to reject any manuscript, to suggest modifications prior to publication, and to edit accepted manuscripts in conformance with Journal style and standards. Manuscripts should be addressed to

\author{
Carlos E. Sluzki, Editor \\ American Journal of Orthopsychiatry \\ School of Public Policy \\ George Mason University \\ 3401 North Fairfax Drive, MS 3B1 \\ Arlington, Virginia 22201-4909
}

